\title{
Animating Brains
}

\section{CORNELIUS BORCK *}

Institute for History of Medicine and Science Studies, University of Lübeck, Königstrasse 42, D-23552 Lübeck, Germany

\begin{abstract}
A recent paper famously accused the rising field of social neuroscience of using faulty statistics under the catchy title 'Voodoo Correlations in Social Neuroscience'. This Special Issue invites us to take this claim as the starting point for a cross-cultural analysis: in which meaningful ways can recent research in the burgeoning field of functional imaging be described as, contrasted with, or simply compared to animistic practices? And what light does such a reading shed on the dynamics and effectiveness of a century of brain research into higher mental functions?

Reviewing the heated debate from 2009 around recent trends in neuroimaging as a possible candidate for current instances of 'soul catching', the paper will then compare these forms of primarily image-based brain research with older regimes, revolving around the deciphering of the brain's electrical activity. How has the move from a decoding paradigm to a representational regime affected the conceptualisation of self, psyche, mind and soul (if there still is such an entity)? And in what ways does modern technoscience provide new tools for animating brains?
\end{abstract}

Keywords: Neuroimaging, Electroencephalography, Epistemology of visualisation, Metaphor, Mediation, Animism

The neurosciences are commonly understood as the scientific project to explore the objective structures and functions of the brain with the aim of explaining its mode(s) of operation. Experimental research on the brain hence shares with the sciences a materialist attitude. Since the beginning of modern brain research some 200 years ago, however, the brain has been conceptualised as the 'organ of the soul' (Sömmerring): for example, as that very part of the human body where immaterial and specifically human features have their seat. ${ }^{1}$ In addition to explaining the anatomy and physiology of the cerebrum, brain research aspired to the status of mind science. Operating across the

* Email address for correspondence: borck@imgwf.uni-luebeck.de

I thank Keith Wailoo for his generous commentary at the workshop 'Soul Catchers - A Material History of the Mind Sciences' at Princeton University. The participants at the workshop and the editors of this special issue provided very helpful feedback and two anonymous referees made extremely valuable suggestions for further strengthening the argument.

${ }^{1}$ Samuel Thomas Sömmerring, Über das Organ der Seele (Königsberg: Nicolovius, 1796); cf. Michael Hagner, Homo cerebralis: Der Wandel vom Seelenorgan zum Gehirn (Berlin: Berlin-Verlag, 1997). 
mind-brain divide, it offered observations, explanations and theories of how the parts and processes within the brain participated in, or generated, psychological processes, cognitive operations and human behaviour at large. In the light of this Special Issue on soul catchers, brain research has - despite its scientific agenda and regardless of its predominantly reductionist framework - always been a soul-catching activity. In this sense, brain research has perhaps 'never been modern', to use Bruno Latour's famous phrase. ${ }^{2}$ Rethinking the history of brain research through the lens of animistic conceptions imported from anthropology may thus help us to come to terms with its dynamics. If material practices in the neurosciences like electroencephalography and, more recently, functional neuroimaging capture an immaterial entity like mental calculation by making it materially real in the form of a written trace or brain scan, they operate by animation, by the infusion of spirit into matter. On basis of such descriptions, the 'soul catcher' is more than a guiding theme of brain research, it emerges as an 'absolute metaphor' in the sense of Hans Blumenberg. As soul-catching, brain research has been a continuing process of 'Umbesetzungen' (reassignments), of attempts to come to terms with the promises of scientific research, that is, to reveal the inner secrets of human nature (Section II). The paper takes the recent debate on 'voodoo correlations' (Section I) as its starting point for comparing two different avenues of experimental research into the brain: functional imaging, as used in the currently flourishing domain of social neurosciences, and electroencephalography, culminating in the idea of 'brainscript' (Sections III and IV). In both cases, the material objects of neuroscientific research practices are defined by their relation to the immaterial, and the immaterial is made practically manageable by its incorporation in the respective scientific objects. The focus on the material practices of brain research is thus meant to offer an alternative and corrective (Section $\mathrm{V}$ ) to a reductive interpretation of objectification according to the standard naturalising epistemology. ${ }^{3}$

\section{Voodoo Correlations}

The catchy title of the publication was the finishing touch in a perfectly orchestrated campaign to alert the world to a striking oddity, an alarming sign (as the campaigners regarded it) of a lamentable lack of scientific rigour. At the end of the year 2008, between Christmas and New Year's Eve, news spread about a forthcoming paper attacking in force the allegedly missing soundness of more or less an entire field of scientific research: 'Voodoo Correlations in Social Neuroscience'. Insiders had already been alarmed before the circulation of the final paper. This was no accident: the authors of the paper had actively contacted all the incriminated laboratories in order to inquire about the details of the statistical methods employed in studies reporting surprisingly high positive correlations between brain activation and psychosocial patterns. By doing so, the authors cleverly combined the rules of open, critical scientific discourse with the incentives of an attentiondriven media society: by giving the defendants a fair chance to prepare against the accusations, they also kindled their interest and focused attention on the publication to come.

\footnotetext{
${ }^{2}$ Latour Bruno, We Have Never Been Modern (Cambridge, MA: Harvard University Press, 1993).

${ }^{3}$ I borrow these summarising sentences together with their succinctness from the superb comments by the referees. Some passages of this paper (in sections I and III) are taken from an earlier version which meanwhile has been published as 'How to Do Voodoo with Functional Neuroimaging', Espace Temps.net 2015, http://www .espacestemps.net/articles/neuroimaging/.
} 
Hence the paper had already circulated the globe in its pre-publication version at an amazing speed, with ever more blogs, mailing lists and discussion groups jumping on. Respected science journals picked up the story in mid-January. 'What were the neuroscientists thinking?', asked the New Scientist in an editorial:

Modern-day neuroscience [...] has produced some wonderful science, including endless technicolor images of the brain at work and headline-grabbing papers about the areas that 'light up' when registering emotions. Researchers charted those sad spots that winked on in women mourning the end of a relationship, the areas that got fired up when thinking about infidelity, or those that surged in arachnophobes when they thought they were about to see a spider. The subjective subject of feelings seemed at last to be becoming objective. Now it seems that a good chunk of the papers in this field contain exaggerated claims, according to an analysis which suggests that 'voodoo correlations' often inflate the link between brain areas and particular behaviours. ${ }^{4}$

The very next day, 15 January 2009, Nature ran an entire page on the story in its news section; ${ }^{5}$ and within a few weeks, literally hundreds of public media had reported on 'voodoo correlations'. 6 The accusations hit like a hammer, perhaps they resonated all too well with the mixture of fascination and suspicion with which the media and the general public tended to follow the regularly spectacular findings in this burgeoning area of the neurosciences. From its beginning, reports about the new methods to visualise the living activity in thinking and feeling human brains had been truly fantastic: thanks to the new visualisation method, readers had been told, social cognition, empathy or aggression, fairness, pain, and anti-social impulses have been revealed to be proper neurobiological entities and no mere social constructions. And now: were all these reports little more but wishful thinking? Had their findings not always been too spectacular to be true?

Now, seven years later, social neuroscience is active as ever, but the debate has been closed, the discussions are over, the intensity of the fires has been forgotten and the smoke settled. The story is still being remembered, although no paper with the title 'Voodoo Correlations in Social Neuroscience' was ever published. Accepted by Perspectives on Psychological Science, the journal editors eventually requested the authors to change the title into the more respectable 'Puzzlingly High Correlations in fMRI Studies of Emotion, Personality, and Social Cognition', 7 All in all, the publication had hardly any long-term effects on the practice of functional neuroimaging; social neuroscience flourishes as before and the findings still count as spectacular. ${ }^{8}$ The field did certainly respond to the critique; in a move to contain the storm, the scientists accused of using problematic methods did evaluate the critique carefully and explicitly. They even addressed the critique publicly and digested it to a certain degree by employing various forms of correction analyses, but the reported correlations between brain and behaviour continue to be 'puzzlingly high'.

Compared to the massiveness of the attack and the weight of the critique, the consequences may be regarded as little, but such a resilience of contemporary neuroscience

\footnotetext{
${ }^{4}$ New Scientist, January 14, 2009, www.newscientist.com/article/mg20126912.800-editorial-what-were-the-neu roscientists-thinking.html.

${ }^{5}$ Alison Abbott, 'Brain Imaging Studies under Fire: Social Neuroscientists Criticised for Exaggerating Links between Brain Activity and Emotions', Nature, 457 (2009), 245.

${ }^{6}$ An overview with links to many of the sources is given by the blog The Amazing World of Psychiatry http: //theamazingworldofpsychiatry.wordpress.com/2009/01/20/voodoo-correlations-in-social-neuroscience/. Daniel Margulies has published reflections about the events from an insider's perspective, see his 'The Salmon of doubt', in Suparna Choudhury and Jan Slaby (eds), Critical Neuroscience: A Handbook of the Social and Cultural Contexts of Neuroscience (Chichester: Blackwell 2012), 273-85.

${ }^{7}$ Edward Vul et al., 'Puzzlingly High Correlations in fMRI Studies of Emotion, Personality, and Social Cognition' Perspectives on Psychological Science, 4, 3 (2009), 274-90.

${ }^{8}$ Edward Vul and Hal Pashler, 'Voodoo and Circularity Errors', NeuroImage, 62 (2012), 945-8.
} 
would simply reflect the field's current power. ${ }^{9}$ And the public resumed its previous attitude, appreciating social neuroscience's spectacular findings as they had embraced the critique a moment ago. After the closure of the debate by the consensus among the experts, little more appears to be memorable but the lost opportunity to engage critically with exaggerated findings and expectations. ${ }^{10}$ Although the story may hardly amount to more than a curiosity, I want to take its headlines as some kind of guiding rod. Instead of reopening the debate on voodoo correlations, ${ }^{11}$ I want to look at it from the point of view of the title and guiding theme of this issue: if modern neuroscience resembles and represents some form of soul catching, what does it mean when actors from within the field call upon animistic concepts such as voodoo for their own arguments, be it for critiquing the science and results of others? ${ }^{12}$

\section{Analogy, Metonymy, and Metaphor: The Animism of the Brain Sciences}

This special issue regards brain research as some kind of soul-catching activity. The 'soul catcher' exists as an object in its own right, well defined within indigenous American culture and used among the shamans of the northern West Coast for dealing with bad luck and incurable diseases. In what sense could one use the name of an object as a descriptive concept? It is an analogy inviting us to compare a specialised area of modern science and experimental research with a non-scientific, non-experimental practice in an allegedly pre-modern religious ritual. But what could be gained from such an intentional blurring of the demarcations between animistic, 'primitive' belief systems and advanced contemporary technoscience? As the special issues invites to review the material cultures of the mind sciences under the notion of soul catching, I want to compare two different strands of experimental work, functional imaging and electroencephalography, with regard to their relative position vis-à-vis soul catching. Contrasting the naturalist epistemological agenda with the material practices and ontological effects of both practices, I shall arrive at determining an analytic value of the concept of animism in (current) brain research.

The soul catcher is a tool for capturing a soul, and for manoeuvring with a spirit like a material object. Souls, spirits, psyches, minds and ghosts are notoriously problematic entities in modern, scientific Western cultures which already resist the classification as thing, object, idea or concept. But precisely because of this resistance, psychological

\footnotetext{
${ }^{9}$ A disclaimer is in place here; 'the neurosciences' simply do not exist as a unified and coherent discipline within a well-defined set of assumptions, methods and theories. With the plural, the name refers to a vast field of highly divergent scientific activities. What I offer is in a decisively limiting sense abstract and full of problematic generalisations. In particular, I cannot do justice to the very heterogeneity of research in the neurosciences, as I focus on practices bridging over the mind-brain divide.

${ }^{10}$ Suparna Chowdhury, Saskia Kathi Nagel and Jan Slaby, 'Critical Neuroscience: Linking Neuroscience and Society through Critical Practice', BioSocieties, 4, 1 (2009), 61-77.

${ }^{11}$ For a more detailed analysis of the debate on Voodoo correlations see Cornelius Borck, 'Comment faire du vaudoo avec l'imagerie cérébrale fonctionelle?', Revue d'Anthropologie des Connaissances 7, 3 (2013), 571-87. 12 One reviewer raised as a potential comparison that also Jacques Monod deployed 'animism' for the purpose of analysing scientific thought. Introducing this term in a chapter of Chance and Necessity: An Essay on the Natural (New York: Knopf, 1971) for describing the projection of teleonomic functioning of the human nervous system in the outside world, Monod then used it for forging a critique of dialectic materialism. Arguing that Marxism conceptualises the subjective experience of thinking as a reflection of natural laws, Monod capitalises on the pejorative normativity of 'animism' in a naturalised epistemology that makes him unwittingly join Vul's corner. There is another important insight to be gained here from Monod's juxtapositioning of animism with vitalism: if animism is the revenant of brain research, biology is certainly haunted by vitalism, for which it is frequently, though not unconsciously, attacked. Cf. Sebastian Normandin and Charles T. Wolfe (eds), Vitalism and the Scientific Image in Post-Enlightenment Life Science, 1800-2010 (Dordrecht: Springer, 2013).
} 
research and the neurosciences may productively be described as soul-catching activities. Taking the historical evidence for the soul catcher as the starting point for the comparison, modern brain research technology could be described as functioning in, at least, a certain respect as a soul catcher (as if it were the product or tool of an animistic culture), leaving aside the question of whether there is any similarity in the entities called 'soul' across the different approaches. Soul catchers were used to capture something immaterial and elusive, and also in the sense of controlling some form of supernatural power. Similarly, brain research technologies capture the immaterial and - in the case of voodoo correlations - control the elusive by banning it from scientific discourse. There are also important obvious differences beyond the analogy. With the arrival of brain sciences and psychological research, their soul catchers now work as instruments for testifying to the existence or non-existence of immaterial powers which were simply assumed to be 'real' by animists - though not necessarily in their Western (re-)conceptualisation.

But what is the result of describing current research in the neurosciences as resembling animistic practices or perhaps even as the revival of some kind of animism? This paper follows the notion of a 'soul catcher' in the form of a heuristic experiment: is it possible to provide a 'thick description' of neuroscientific research and its effects as animistic practices in an ethnographic perspective and what do we gain from it? ${ }^{13}$ A few comments are required in order to prevent easy misunderstandings: the comparison is based on the assumption that some new understanding of neuroscientific research practices could be yielded. Hence, the impulse is neither ironic nor cynical, although at first glance such a description must appear as a ridiculing approach, ignorant of the indisputable progress in brain research, the neurosciences and psychology. In a situation where radical critiques come from within the field (as exemplified by the Voodoo paper) and where critics take an active role in shaping the discipline by means of philosophical analyses (as demonstrated by the 'critical neuroscience group', for example), a search for 'animistic practices' may provide a fresh start for identifying true 'matters of concern' when a more traditional type of 'critique has run out of steam'. ${ }^{14}$ Describing current research practices by means of concepts foreign to the field (soul catchers, voodoo, animism) may be a way for moving beyond disciplinary boundaries and separating lines often drawn by the scientific practitioners, in order to reach a discussion space beyond the research agendas driving it.

Animism was once a concept for describing allegedly 'primitive' religions in a Eurocentric perspective. ${ }^{15}$ Conceptualising 'animism' as a primitive form of religion obviously followed from a colonialist European perspective upon non-European cultures. Animism owed its plausibility to the newly established evolutionary framework, separating more advanced cultures in terms of modern rationality from others. As part of the normative, modernist agenda of the concept, 'animism' was held to be a pre-modern social and psychological mechanism by means of which nature and things were erroneously

\footnotetext{
13 The term is obviously borrowed from Clifford Geertz, 'Thick description: toward an interpretive theory of culture', in Clifford Geertz The Interpretation of Cultures: Selected Essays (New York: Basic Books, 1973), 3-30.

${ }^{14}$ Suparna Choudhury and Jan Slaby (eds), Critical Neuroscience: A Handbook of the Social and Cultural Contexts of Neuroscience (Chichester: Blackwell, 2012); Bruno Latour, 'Why Has Critique Run out of Steam? From Matters of Fact to Matters of Concern', Critical Inquiry 30 (2004), 225-48.

15 In this meaning, animism is usually traced back to Edward Burnett Tylor, who included a chapter on it in his Primitive Culture: Researches into the Development of Mythology, Philosophy, Religion, Language, Art and Custom (London: Murray, 1871), Vol. 1, 377-453, defining his use of the term on p. 384: 'I purpose here, under the name of Animism, to investigate the deep-lying doctrine of Spiritual Beings, which embodies the very essence of Spiritualistic as opposed to Materialistic philosophy.'.
} 
endowed with souls and agency. ${ }^{16}$ In this way, animism implicitly addressed many epistemological problems back in Europe at the time. Accordingly, a wave of critical scholarship in ethnography and religious studies assigned 'animism' to the dustbins of history. More recently, however, and in conjunction with the problematisation of the nature/culture dichotomy, the concept was revived precisely for critiquing such rigidly modern and dichotomist epistemologies of subject/object, nature/culture, and rational/irrational, thereby repositioning and refiguring animism as a core example for a relational epistemology. ${ }^{17} \mathrm{Re}$-investigating the research agendas from various branches of brain and psychological research in relation to their multiple effects, the 'soul catcher' special issue has something similar in mind.

From such a perspective, the term 'soul catcher' does not so much function as an analogy opening ways for comparing modern regimes of research to earlier religious practices, but as a metonymy pointing to the multiple and multiplying effects of a naturalising research practice. As a metonymy, 'soul catching' emphasises a strange proficiency of brain research to contend and nurture concepts like psyche, mind, spirit or affect. Bridging the gap between the history of ideas and historical epistemology, one could even investigate, how the conceptualisation of 'animism' intertwined with, or paved the way for, the emergence of the psyche as a research object. With its polemical and ideological implications, the normative and out-dated concept of 'animism' will not solve current epistemological problems; but as a descriptive term it may acquire new meanings for capturing the eerie qualities of scientific practices themselves, pointing to the paradoxical and animating effects of endorsed technological and scientific practices as the flip side of rationalism and the belief in progress. The analytic value of the concept of 'animism' lies less in capturing some newly acquired characteristic of the neurosciences, as the term is not applied here to distinguish a recent detour of allegedly softer branches of brain research from a properly objective form of conducting experimental research. On the contrary, the term is employed here for describing some of the larger trajectories and productivity of brain research beyond the reported scientific breakthroughs by cutting through traditional and methodological demarcations between science and non-science, rational and irrational, or real and mythical.

Building on the anthropological scholarship on scientific practices, such a mobilisation of 'animism' as a descriptive term for characterising the effects of modern and current research in the mind and brain sciences turns the concept full circle. If animism is a key concept in anthropology with a long and problematic history, which eventually became decisive for widening the Eurocentric and limited scope of Western notions of reasoning and rationality, it may be possible (in the light of the value of ethnographic methodological apparatus for analysing the scientific laboratory as the closed centre of knowledge production in modern Western culture) to garner its potential for capturing some of the more ambivalent effects and consequences of Western scientific practice. The aim is not to deride modern science as primitive or simply 'the same', but to apply the analytical and methodological rigour of ethnographic studies together with

${ }^{16}$ Cf. Anselm Franke, 'Much trouble in the transportation of souls, or, the sudden disorganization of boundaries', in Anselm Franke (ed.), Animism, Vol. 1 (Berlin: Sternberg, 2010), 11-53.

${ }^{17}$ Eduardo Batalha Viveiros de Castro, 'Exchanging Perspectives: the Transformation of Objects into Subjects in Amerindian Ontologies', Common Knowledge 10, 3 (2004), 463-84; Tim Ingold, 'Rethinking the Animate, Re-animating Thought', Ethnos 71, 1 (2006), 9-20. A multinational exhibition project used the term 'animism' for 'revisions of modernity' and convened scholars like Michael Taussig, Isabelle Stengers or Tobie Nathan for a discussion on 'other narratives of modernity', cf. Irene Albers, Anselm Franke (eds), Animismus: Revisionen der Moderne (Zurich: Diaphanes, 2012). 
their openness in deriving unexpected insights. If brain research shares certain qualities and effects with soul catching, perhaps the neurosciences, and some strands of brain research from the late nineteenth century onwards, were driven and are driven by similar forces. Or the dynamics of neuroscientific research can perhaps still be attributed to some supernatural underpinnings of the research objects and aligned with unresolved tensions in the respective scientific world views.

'Animating brains' may then become a way for describing such tendencies not just as unintended side effects of rational research and scientific progress, but as an underlying structure indicative of formative forces in such research. 'Animism' is meant here as an analytic concept for highlighting the material engagement of brain research in capturing immaterial entities. ${ }^{18}$ The delineation of an anatomical pathway connecting the different brain areas engaged in translating written words in speech, the traces of electric brain activity recorded from a subject engaged in calculation, the patterns of activation visualised during an empathy test in a scanner are just three examples from different periods of brain research, demonstrating an intertwining of spirit and matter as the very aim of the experimental practice. Within the rationalist framework of scientific research, these investigations may be explained as experimental approaches to the brain for objectifying mysterious, irrational or ill-founded concepts. From an ethnographic perspective however, these practices share with the soul catcher that the material object under investigation is defined by its relation to the immaterial. In addition, such a series of changing versions of animism in brain research would give an almost perfect example for what the German philosopher Hans Blumenberg coined 'Umbesetzungen'. According to him, the history of ideas is not so much a chain of solved research questions but a series of changing responses to continuing metaphysical questions in which the old answers are evacuated. Blumenberg derived Umbesetzungen from his analysis of the period of the scientific revolution, ${ }^{19}$ but generalised it for the process of secularisation - of which brain research would obviously be an example, although Blumenberg did not comment on it.

In Blumenberg's philosophy of conceptual history, the concept of Umbesetzungen is linked with a re-appreciation of metaphors as original and rich forms of conceptualisation in contrast to the precisely defined and distinct meaning of scientific concepts, always limited to the horizons of the discipline. Precisely by their very nature, scientific terms fail to acknowledge metaphysical needs, replacing them by scientific explanations, whereas the richness and indeterminacy of metaphors, especially of 'absolute metaphors' address and answer such metaphysical questions. ${ }^{20}$ Going along with such an argument, the term

\footnotetext{
${ }^{18}$ Here is not the place to engage more critically with the discourse on animism and its different conceptualisations. My use of the term is admittedly vague for the purpose of ascertaining what I take to be an important and hitherto neglected characteristic of brain research. I do not, for example, follow Philippe Descola's more specific definition of 'animism' as the attribution of life to non-human entities. Brain activity, brain structures or activation patterns certainly 'are' human entities, but describing the management of these scientific objects in brain research nonetheless as a form of animism, I might add, follows from the intuition (which I cannot prove here) that the particular value of these scientific objects hinges upon them being externally accessible material objects. In my view, brain research would provide an excellent and important field for elaborating further Descola's argument that nature is not what is left of the world if stripped of culture, (Chicago, IL: University of Chicago Press, 2013).

${ }^{19}$ Hans Blumenberg, The Legitimacy of the Modern Age (Cambridge, MA: MIT Press, 1983).

${ }^{20}$ Hans Blumenberg, Paradigms for a Metaphorology (Ithaca, NY: Cornell University Press 2010). On Blumenberg's potential for a historical epistemology, see Cornelius Borck, 'Philosophie als "Transzendenz nach innen": Einleitende Bemerkungen zu Hans Blumenbergs Ortsbestimmung der Philosophie zwischen Wissenschaft und Technik', in Cornelius Borck (ed.), Hans Blumenberg beobachtet, Philosophie, Wissenschaft und Technik (Freiburg: Karl Alber, 2013), 9-22.
} 
'soul catcher' can be read as an absolute metaphor: many psychological experiments and research in the neurosciences share the aim of capturing the soul (or one of its derivatives), this still central concept of human nature, regardless of its elusiveness. Although brain research and neuroscientific theories with their definitions, calculations and models necessarily fail to meet the demand for existentially satisfying answers about the core of the self and human nature, experimental research and modern technology come up with ever more subtle strategies for registering traces of its activity. If there is, so far, no escape from materialising the soul, perhaps it is time to think of ways for accommodating the soul-producing effects of scientific research, precisely as there are so many mindful practices under the sun, in and outside of brains.

\section{New Ontologies within a Reductionist Epistemological Framework}

At first glance, two hundred years of scientific experiments in brain research have succeeded in purifying the world of spirits, ghosts and strange immaterial powers. In the pure and bright searchlight of scientific experiments guided by the enlightened reasoning of scientific rationality such ghosts and supernatural forces have been declared superstitions, and research into the psyche, the brain and the mind by the neurosciences declaredly relinquished them to the dustbins of history. After some drawbacks because of unexpected new openings for supernatural powers by new media technologies around 1900 and with the arrival of the Decade of the Brain at the turn of the millennium, neuroscientific research has apparently succeeded with its programme of identifying the natural parts and processes responsible for generating psychological and cognitive activities. The soul was first relegated to the head, where it was then explained as the mind-side and the affective inside of a purely natural, material brain, structured by evolution, genetics and anatomy, governed by the laws of neurophysiology.

This naturalised and naturalising epistemology still holds; there are no ghosts under the sun, not even inside the brain. Along this trajectory, however, social neuroscience populates the world with a surprisingly large number of entities which until now had been regarded as of ambivalent if not dubious ontological status, because hitherto they had clearly fallen outside the realm of material objects. ${ }^{21}$ Social neuroscience does not populate the world of human beings with mysterious objects of an unknown quality or dubious ontology: it operates within a strictly naturalising epistemology. However, it demonstrates psycho-social and cultural entities to be proper neurophysiological states with well-defined cerebral substrates in the form of specifically activated brain regions or neuronal networks. During the nineteenth century, from lesion studies and postmortem examinations, neuroanatomists identified specific brain regions as responsible for sensory processing or speech recognition. Today, their colleagues in neuroimaging dissect the functional anatomy of the brain into its finer and more sophisticated social operations within the reigning reductionist paradigm that has been driving basic research

21 The neurosciences managed not just to establish themselves as the central institution for discussing and debating claims about the soul, but also to keep supernatural psychic powers alive by declaring their aim of purifying the world of such irrational and wrong beliefs. Studying a different field, Michel Foucault developed a similar argument for describing the endless focusing of society on sex during the 19th century as the unintended consequence of the Victorian morality, cf. Michel Foucault, 'We "Other Victorians", in The Will to Knowledge: The History of Sexuality, Vol. 1 (London: Penguin 1990), 1-15. As far as I can see, the argument of epistemological reductionism in combination with ontological multiplication, on which I elaborate here, was first presented by Martyn Pickersgill, 'Between Soma and Society: Neuroscience and the Ontology of Psychopathy', BioSocieties 4 (2009), 45-60. 
in the neurosciences for more than a century. Already back then, the brain's anatomical organisation provided strong evidence for far-reaching and even speculative inferences, suggesting, for example, the neuronal connections as the material infrastructure of thinking according to the concept of associationism. But, unlike the neuroanatomists, the neuroimaging researchers animate these structures as the vividly active network of the living brain.

Hence, a while ago, the advent of functional imaging re-kindled older debates about phrenology, the free will and human intentionality. Before functional neuroimaging, there was no conceivable way to determine, for example, fairness as an objective brain state, apart from Franz Joseph Gall's comprehensive phrenological chart from two hundred years ago, attributing all psychological faculties considered culturally relevant a seat in the brain. With the availability of functional imaging and especially with the emergence of social neuroscience, fairness like empathy, aggression or revenge have been characterised as functional human brain states of specific determinations. Accordingly, functional imaging was quickly accused of re-engaging in an out-dated form of phrenology. ${ }^{22}$ In terms of soul catching as an absolute metaphor, the recurrence of the idea of pinpointing psychic activity to specific brain regions within a radically different scientific paradigm after two hundred years is certainly striking, but so are the differences in the brain sciences' new animism. Anatomical localisation and physiological centres of control no longer dominate the theorising about the brain.

Social neuroscience does not address such issues in the same way, there is no search for freedom, for example, or the centre of decision-making. Based on experiments with event-related potentials, Benjamin Libet felt forced, from the 1960s onwards, to formulate a complex theory of vetoing in the light of the experimental evidence from his search for the functional anatomy of human decision-making, and many colleagues discarded human freedom altogether. ${ }^{23}$ Meanwhile, the fierceness of these discussions has much lessened. The radical reductionism from the days of the Decade of the Brain may not have disappeared entirely, but it certainly has lost much of its grip on the field. Social neuroscience takes a somewhat withdrawn position with regard to psychic interactionism; it certainly demonstrates social interaction to be the cause of distinctive responses in human brains but it does not arrange this evidence in a revival of an old-fashioned dualism arguing for some form of psychic causality beyond physiological mechanisms. Social neuroscience does not engage in any psychism of this sort. Obviously, social neuroscience is not about declaring social cognition to be something immaterial or spiritual outside human brains, but it demonstrates that meditation and other spiritual practices physiologically affect the human brain. ${ }^{24}$

From a philosophy-of-science perspective, one may argue that this research still pursues an epistemological reductionism, when it extends the realm of natural scientific research into the social. But the ontologies of functional imaging, with their steadily growing number of new entities taken from the world of social interactions that are now furbished with a neurophysiological substrate, create new families of hybrid objects, half social

\footnotetext{
22 William R. Uttal, The New Phrenology: The Limits of Localizing Cognitive Processes in the Brain (Cambridge, MA: MIT Press, 2001).

${ }^{23}$ Benjamin Libet, Mind Time: The Temporal Factor in Consciousness (Cambridge, MA: Harvard University Press, 2004).

${ }^{24}$ A telltale example is offered by the activities of Tania Singer's group at the MPI for Human Cognitive and Brain Sciences in Leipzig, see http://www.cbs.mpg.de/depts/singer/arb3.
} 
constructs, half scientific objects, furbished with a natural basis by the neurosciences. They are nature/culture hybrids. They share their nature as hybrids with many objects currently under investigation by the sciences, which have come into being as constructed natural objects by means of the technoscientific arrangements of experimental practices as observed by philosophers and sociologists of science from Gaston Bachelard to Bruno Latour. ${ }^{25}$ But the new brain states are hybrids in a new form, since they are not artificially made or technologically created in the same mode as other natural objects.

Like genes or quarks, 'empathy' as a naturalised entity relies entirely and exclusively on a complex ensemble of technoscientific practices bringing it into existence and stabilising it as a scientific object; but unlike genes or quarks, 'empathy' arrived in the lab from the lifeworld of modern society. Social neuroscience operates in reverse direction, taking its objects from the realm of culture and turning them into natural objects. In addition, these newly naturalised objects established by social neuroscience are supposed to operate in the physiological spaces of the living brain: they function in the visualisation practices surrounding the scanner, and on the macro level of human interaction; they work according to the symbolic logic of culture. In this regard, social neuroscience establishes natural objects with more-than-natural qualities. Quite generally, functional neuroimaging brings artificial neuroscience and dead brain sciences closer to life and to real life human beings; it literally animates its objects under investigation by linking a perfusion pattern with psychic, social and cognitive significance. ${ }^{26}$ Anthropology once described such practices of creating more-than-natural natural objects as 'animism'. The soul catcher is an example which may also be applied to the mind sciences. 'Voodoo' was the term the authors had initially chosen for simply pointing to the unsound statistical basis of the burgeoning field of social neurosciences without further clarification why they had picked this term from the family of animistic concepts. Read in the context of ethnographic science studies, the title of Vul's paper acquires another layer of meaning, adding another twist. ${ }^{27}$

From an animistic epistemological perspective, one consequence of the flourishing of social neuroscience is particularly noteworthy, although never explicitly addressed during the debate on 'Voodoo Correlations'. With social neuroscience, scientific research addresses questions of general interest today by means of scientific research and in a style apparently directly relevant for society at large. Social neuroscience reveals social cognition to be something materially real, neurophysiologically realised, regardless of all questions from cultural relativism or social constructivism. With its constructive powers, neuroscience has helped to establish a growing array of new objects. After an entire century of focusing on the psyche and the mind sciences, the coming true of the old dream of deciphering the brain as the fundamental machine in charge of all higher human activities has appeared on the horizon.

\footnotetext{
25 Gaston Bachelard, The New Scientific Spirit (Boston, MA: Beacon Press, 1985); Bruno Latour, op. cit. (note 2).

${ }^{26}$ Cornelius Borck, 'Animism in the Sciences Then and Now', e-flux Journal, 36 (2012), http://www.e-flux.com /journal/animism-in-the-sciences-then-and-now/.

${ }^{27}$ For the purpose of this paper, I take the appearance of this term in a neuroscientific research publication as a discursive event offering the opportunity for an interpretation from a different angle. I cannot engage here in the ethnographic discussion of this concept, cf. Nicolas Vonarx, Le Vodou haïtien: Entre médecine, magie et religion (Rennes: Presses Universitaires de Rennes, 2011).
} 


\section{Mind Reading}

The current fascination surrounding functional neuroimaging is reminiscent of the attraction another visualisation technique yielded earlier in the twentieth century: electroencephalography, the recording of the brain's intrinsic electric activity from the human head. ${ }^{28}$ In both cases, a new method kindled far-reaching speculations, especially the potential of tracking the mind by physiological means. Electroencephalography revealed a direct and strange correlation to mental processing. Simply by looking at the recording, scientists were able to determine when a person engaged in a task such as mental arithmetic, how long she concentrated on it and when the task was finished. Back in 1930, a journalist summarised succinctly the hopes kindled by these new methods: 'Today the brain writes secret code, tomorrow scientists will be able to read neuropsychiatric conditions in them, and the day after tomorrow we will write our first authentic letters in brainscript. ${ }^{29}$ The recording machine accessed the operations of the brain machine at the level of its intrinsic organisation, or so it seemed. Electroencephalography revealed electric potentials in the well-structured form of brain waves and it supposed this system of potentials to be a kind of language, a 'brainscript' awaiting to be deciphered, as the commentator in the German newspaper had put it. The writings produced by the machine resonated with the brain's mode of operation, recording the activity along the neurons' communication system as a code awaiting its deciphering as meaningful language. Writing, the writing of the recording machine, so it appeared, was the missing link between mind and brain.

With the idea of brainscript, electroencephalography revived Marey's famous promise that "the graphic method [would] translate [... ] changes in the activity of [bodily] forces in a striking manner which one could call the language of the phenomena themselves' ${ }^{30}$ The idea also pushed electroencephalography in a new direction: brainscript was the language of the brain's neurons, and beyond that, it was also 'our' language, the code of human thinking and feeling. Brainscript shared an affinity to natural language with the various graphic recordings that had dominated physiology since the second half of the nineteenth century; but brainscript operated at the same time on the symbolic plane, the language side of the nature/culture divide. If humans were the 'symbolic species', here the key for the interaction between physiological signalling and the codes of cultural communication were to be found. ${ }^{31}$

This hybrid character of the EEG, being a natural phenomenon full of implicit cultural connotations, guaranteed that it would harvest enormous and immediate public attention. It was hoped that the new method would provide the means to decipher the brain at work in human culture. The scientists involved in this research were certainly careful not to draw too fantastic or spectacular a conclusion. But the quick dissemination of the new method, the rapid establishment of new groups specialising in electroencephalography across the entire Western world, mirrored a widespread and deep intellectual investment

\footnotetext{
${ }^{28}$ Cf. Cornelius Borck, Hirnströme: Eine Kulturgeschichte der Elektroenzephalographie (Göttingen: Wallstein 2005).

${ }^{29}$ W. Finkler, 'Die elektrische Schrift des Gehirns', Neues Wiener Journal, 4 (1930).

${ }^{30}$ Etienne Jules Marey, La Méthode graphique dans les sciences expérimentales et principalement en physiologie et en medicine (Paris: Masson 1878), vii.

${ }^{31}$ By referring to the title of a book by Terrence W. Deacon, The Symbolic Species: The Co-evolution of Language and the Brain (New York: Norton, 1997), I use the term deliberately ignoring the linguistic differentiation between symbols and signs, as precisely this vagueness was characteristic of the field.
} 
in electroencephalography. ${ }^{32}$ The initial experiments had revealed little more than a correlation, a peculiar withdrawal of the regular brain waves in phase with mental processing, but this was an indisputable and promising trace of psychophysiological interaction. From the very beginning, scientists conceived of brainwaves as mediators, anchoring the cultural fabric of human activities in the world of the biological, thereby conflating the linguistic difference between the sign and the signified to the 'meaning' of the recorded physiological potential.

A particularly spectacular EEG experiment took place at the end of the year 1951 . In fact, the result of the experiment was not so spectacular, but the event itself was: it was a kind of brain wave contest between three scientific geniuses, Albert Einstein, John von Neumann, and Norbert Wiener. Above all, this experiment demonstrated the appeal and ineradicable persistence of the idea of brainscript. Unfortunately, only one result has been published. Neither the EEG of the theory of computation nor that of cybernetics has been made available, only the EEG of the theory of relativity, or to be more precise, the visualisation of the electrical activity of Einstein's brain while he was asked to think of the theory of relativity. Roland Barthes famously remarked on this photo:

A photograph shows him lying down, his head bristling with electric wires: the waves of his brain are being recorded, while he is requested to 'think of relativity'. (But for that matter, what does 'to think of' mean, exactly?) What this is meant to convey is probably that the seismograms will be all the more violent since 'relativity' is an arduous subject. Thought itself is thus represented as an energetic material, the measurable product of a complex (quasi-electrical) apparatus which transforms cerebral substance into power. ${ }^{33}$

As if to testify to the confusion underlying the attempt to decipher the significance of the theory of relativity by physiological means, the brain wave recorder reported, on all its eight channels, nothing but a strange withdrawal of the event to be observed.

This may have been different in the case of the famous cybernetician, as he had come up with his own theory about brain waves. Wiener was not making light of his contributions to the field when he recommended his conceptualisation simply as the 'Rosetta stone' of electroencephalography:

[Brain waves] speak a language of their own, but this language is not something that one can observe precisely with the naked eye, by merely looking at the ink records of the electroencephalograph. There is much information contained in these ink records, but it is like the information concerning the Egyptian language which we had in the days before the Rosetta Stone. [. . . When the crude original records of brain waves are transformed by the autocorrelator, we obtain a picture of remarkable clarity and significance, quite unlike the illegible confusion of the crude records which have gone into the machine. ${ }^{34}$

For Wiener, the Rosetta stone of electroencephalography was a sharp peak in the band of alpha frequencies, at exactly $9.05 \mathrm{~Hz}$. Wiener conceived the precision of the alpha rhythm to be an indicator of intelligence. The sharpness of a peak in the autocorrelogram would mirror the accuracy of mental processing.

The comparison with hieroglyphs was certainly meant to point to the success in deciphering a secret code. In addition, Wiener conceived of brain waves as 'hieroglyphs' in the sense that they were bridging a gap between a physiological mode of operation and a cognitive potential. In Egyptian writing, the abstract meaning of the symbolic code is anchored in the iconic reality of the depicted. According to Wiener, brains resembled

${ }^{32}$ Cornelius Borck, 'Recording the Brain at Work: The Visible, the Readable, and the Invisible in Electroencephalography', Journal of the History of the Neurosciences, 17 (2008), 367-79.

${ }^{33}$ Roland Barthes, Mythologies, selected and translated from the French by Annette Lavers (New York: Hill and Wang,1972), 68.

${ }^{34}$ Norbert Wiener, I Am a Mathematician (Cambridge, MA: MIT Press, 1956), 289. 
computers not only abstractly in respect of their calculation capabilities, but also in using similar mechanisms of data processing and an internal clock for the timing of computation. His theory thus simply added a calculus to his intuition, but it was hardly a Rosetta stone. First of all, the experiments did not confirm his intuition and no proper correlation between the stability of the alpha rhythm and intelligence could be established. But even if such a relation had been observed, his hypothesis would still not have been the Rosetta stone, for Wiener's intuition provided a key to deciphering brain waves not as a language but as the mere operating mode of a machine. Rewriting the EEG as an autocorrelogram extinguished any meaning for the purpose of accessing the hardware involved in the coding mechanism.

Wiener mobilised MIT's recently acquired digital computing powers for this task. Yet autocorrelation analysis was but one way to proceed; what about other frequencies or the relative distribution of rhythms in time or space? What about phase relations or periods of synchronisation? There were ample opportunities for very different forms of analysis and visualisation, as testified by the proliferation of new approaches to recording, displaying and analysing brain waves that Walter, Wiener's British counterpart, reeled off. ${ }^{35}$ His laboratory in Bristol transformed into a zone of symbiosis or co-evolution of human minds and machines: 'The machines that flash and click in our laboratories now are the first forms of the living brain's extended life, the rudiments of racial understanding, as Gutenberg's first printing presses were the forerunners of the Reformation. ${ }^{36}$ Walter's tinkering with radar and television screens, flicker lamps, vacuum tubes and frequency analysers created an epistemological space that rotated less around the confirmation of a theory than around the productivity of a technological ensemble for envisioning the brain's new life.

Walter had attended the first public demonstration of an EEG by Douglas Adrian in 1934 at a meeting of the Physiological Society in Cambridge, and back then, he had written a report about this experiment for the Spectator concluding with the remarkable statement: 'So, with this technique, thought would seem to be a negative sort of thing: a breaking of the synchronised activity of enormous numbers of cells into an individualised working. ${ }^{37}$ He spent his life proving the contrary. His EEG research continued to generate new theories, as human brains continued to send encrypted signals worth every new form of visualisation. But the solution that had seemed, in 1934, to be so close has long since vanished in the information amassed.

\section{Image and Logic in the Neurosciences}

More than half a century separates the two examples I compare here and they come from two radically different quarters of experimental investigation. Research in the neurosciences has conveniently been divided into two main subfields, the morphological or anatomical tradition, and the functional or physiological tradition. Describing these disciplinary specialisations as the ideal type in Max Weber's sense, the morphological tradition differs from the functional in approach, methods and the information derived thereby, in its aim of identifying and characterising the shapes and structures of the brain's various parts, whereas functionalist approaches focus on the recording and observing of an organ's operations over time. The former line of research concentrates on form and stable entities, the latter on process and change. With the advent of functional imaging, however,

\footnotetext{
${ }^{35}$ Rhodri Hayward, 'The Tortoise and the Love-Machine: Grey Walter and the Politics of Electroencephalography', Science in Context, 14 (2001), 615-41.

36 W. Grey Walter, The Living Brain (London: Duckworth, 1953), 193.

37 Ibid.; 'Thought and Brain: A Cambridge Experiment', Spectator , 153 (1934), 478-9: 479.
} 
this divide appears to have been bridged, as functional imaging combines structural information with activation patterns. It is precisely this technological advancement that has been celebrated and embraced as the final breakthrough for coming to terms with the brain as the organ of the soul. While this enticed a group of German neuroscientists to publish about a decade ago a notorious 'manifesto', stating that neuroscientific progress would imminently demand appropriate measures of adaptation by society, ${ }^{38}$ the dynamics of this branch of research have meanwhile washed away such a reductionist vision. The emergence of new research fields like social neuroscience points in different directions, where the new methods get employed exactly for searching into the liminal spaces of social cognition, meditation or affective reasoning. Functional imaging has emerged as a soul catcher, a strategy for animating brains to the highest hopes for a blending of mind and matter.

Regardless of the declared breakthrough in combining structure and function, there are important differences between the two approaches of EEG and fMRI that are reminiscent of Peter Galison's famous distinction between image and logic. ${ }^{39}$ Certainly, the neurosciences were never as clearly divided into experimental and theoretical branches as physics, with its institutional partitioning. And yet, the main strength of Galison's book is precisely not to have written a history of modern physics along the dividing line of experiment and theory. Image and Logic divides research in particle physics according to the material culture of instrumentation and thus embeds experimentation in the rich thicket of things. Like research in particle physics, the neurosciences are very much organised around instrumental practices. In contrast to physics, however, all branches of the neurosciences rely on one form of visual evidence or another, there is hardly any 'anti-visual' strand in brain research. But Galison characterised his two groups more specifically. The first tradition, based on images, he also described as a mimetic and homomorphic mode of representation, preserving the form of things as they occur in the world; while the second, the logic tradition, he characterised as a homologous mode of representation, preserving the logical relations among events. And with these characterisations, the mimetic versus the homologous, it seems possible to construe the neuroscientific analogues.

In the mimetic approach, images stand for themselves as they give evidence of cells, fibres, tracts, and traits or structural specialisations. In the mimetic approach to anatomical research practices, there is a relationship of similarity between the structure and the images. The images demonstrate structures: they show where and what something 'really' is. The mode of representation is the objectivity of the photograph; its mode of information is physical contact rather than symbolic communication. In the homologous tradition, by contrast, visual evidence predominantly comes as an image of a process - a trace or a signature of a function. Although here as well as in the other tradition the images are, physically speaking, spatial objects, their status as functional visual evidence hinges on their ability to capture temporal relations as functional processes. They preserve functional relations, whereas their spatial resolution is notoriously weak. Because of the almost complete absence of a mimetic relation between the visual evidence and the phenomenon

${ }^{38}$ C.E. Elger, A.D. Friederici, C. Koch, H. Luhmann, C. von der Malsburg, R. Menzel, H. Monyer, F. Rösler, G. Roth, H. Scheich and W. Singer, 'Das Manifest: Elf führende Neurowissenschaftler über Gegenwart und Zukunft der Hirnforschung', Gehirn und Geist, 3 (2004), 31-7.

${ }^{39}$ Peter Galison, Image and Logic: A Material Culture of Microphysics (Chicago, IL: University of Chicago Press, 1997). 
captured, the images from this tradition typically do not reveal or display their content at first glance. Their information is coded and hence must be extracted, not by looking at them, but by a form of deciphering and reading. In this tradition, images are not drawn or photographed but written, recorded. Hence there is an intimate link to language in this mode of representation, which Wiener alluded to in his comparison of the EEG with the Rosetta Stone. Because one could not 'see' anything in the EEG recording, a large variety of readings and interpretations have been propagated; the EEG fostered a logical approach to the living brain. Functional imaging also visualises activation but it does so in the mimetic mode of representation; functional imaging suggests 'looking at the brain at work', although the 'realism' of its representations is the product of sophisticated artificial algorithms.

This may be too abstract a generalisation and will certainly require much more cultural contextualisation to forge a historical argument. However, the differentiation between these two approaches may suffice for a philosophical reflection: because of its intimate connection between the mimetic representation and the supposedly depicted phenomena, the homomorphic tradition engages rather easily and swiftly in objectification, whereas the logic tradition has more often been employed by researchers leaning towards functionalism and emergentism. ${ }^{40}$ This is more than a question of style or taste, especially if the historical analysis holds that brain research is soul catching in the sense of a Blumenbergian absolute metaphor, that is, the striving for the 'whole picture', for answers leaving no questions open. The mimetic approach is 'objectifying' not only in sense of the underlying naturalised epistemology but also as a mode of production, resulting in the new ontologies of multiples, the dynamic hybrid objects of social neuroscience. This tension between the two modes of objectification appears to be hardly resolvable within the scientific agenda of the neurosciences, as long as this process is perceived and discussed solely from the perspective of a naturalised epistemology where it simply appears as an indisputable advance of scientific, empirical, objective research.

The very dynamic of this research, however, as here observed as an example of Umbesetzungen, escapes such a narrative of rational progress. Instead, there are remnants of animism within the reductionism of social neuroscience, they are irreducible like Blumenberg's absolute metaphors. The animistic qualities of brain research transgress the narrow limits of the acknowledged epistemological framework and hence they may go unnoticed though perhaps not unnoticeable. Occasionally they may hit like magic, as some kind of return of the irrational, as was the case when someone dared to label social neuroscience voodoo and the public picked up the story by storm. In 'Voodoo Correlations in Social Neuroscience', Ed Vul and his co-authors used 'voodoo' as a stigmatising label, dramatising their accusations to fight against uncritical and non-scientific activities within the sciences. ${ }^{41}$ Although they lost the debate, they succeeded in gaining enormous attention and Vul won professional recognition. ${ }^{42}$ The scientists accused by Vul and his co-authors of publishing unsound data convinced the public and funding organisations that their science was sound, and, as a consequence, these allegedly voodoo correlations

\footnotetext{
${ }^{40}$ Here, I rely on discussions with Frank Stahnisch who has recently published a similar outline of research trajectories in the neurosciences: Frank W. Stahnisch, 'The Language of Visual Representations in the Neurosciences: Relating Past and Future', Translational Neuroscience 5, 1 (2014), 78-90.

${ }^{41}$ Their paper reminded readers of Robert L. Park, Voodoo science: the road from foolishness to fraud (New York: Oxford University Press, 2000).

${ }^{42} \mathrm{He}$ was offered an academic position in the Department of Psychology, University of California at San Diego.
} 
had to be taken seriously. So, Vul had a point and missed it in the way he styled his attack: voodoo, rejected by the scientific community as a qualification of problematic methods for statistical analysis, re-enters as a descriptive category of scientific practice in social neuroscience.

Functional neuroimaging constitutes animated natural objects - and the scientists, together with the general public, happily embrace the method for precisely this effect. Social neuroscience is but one strain of a larger shift away from traditional reductionism; a new 'neuroculture' is emerging which is still difficult to grasp or to acknowledge. ${ }^{43}$ The new dynamism within the neurosciences takes many different manifestations, from mirror neurons and neuronal plasticity to experiments employing the scanner as a feedback device for therapeutic interventions. Together, they form an ensemble of highly appreciated concepts, because of the new emphasis on dynamic aspects. It is, in this regard, a family of animistic concepts by which human culture may enter a stage of soul catching as interactive brain work. Almost a century ago and observing the emergence of film and cinema, Walter Benjamin contemplated a potentially liberating power of new media technologies, calling for an 'alliance technology', designed not to conquer but to liberate human nature. ${ }^{44}$ According to him, such a technology would have to encompass some form of collective innervation, opening up new spaces of interaction and intervention. Today, we are perhaps witnessing a transformation in this direction - possibly without grasping its liberating potential. Overcoming the limits of human nature has been an old dream, revived with almost every technological innovation and revitalised in particular with the new bio-technologies and information technologies. With the neurosciences now focusing on the plasticity of dynamic, open interactions, the goal of at least this branch of the neurosciences is no longer the complete deciphering of the brain's anatomy, physiology, or programmed functionality, since these no longer determine mindful activity. The future of the neurosciences has become the open, animated brain.

The neurosciences, however, are too heterogeneous a field for such a monolithic conclusion. Coinciding with the rise of neuroplasticity and the social neurosciences analysed here with the concept of animism, two massively collaborative research projects started to harvest the power of large-scale computing for modelling a human brain as a stable entity by collecting available data on all scales, from synaptic trafficking and anatomical connections up to macroscopic structures like the fibres, tracks and activation patterns within the human brain. The European Union's recently started Human Brain Project and the BRAIN Initiative announced by the Obama administration may thus escape the kind of animism described here, but already by their acronyms they provide perfect examples of absolute metaphors. ${ }^{45}$ The question of whether any of the brains to be materialised by these lines of research will be a utopian brain in Benjamin's sense or just exemplifying another Umbesetzung, remains open - as research questions are always

${ }^{43}$ Fernando Vidal, Nikolas Rose and others have described how the neurosciences mobilised the human brain to function more and more as the centre stage for, and supposed essence of, human nature, Fernando Vidal, 'Brainhood, Anthropological Figure of Modernity', History of the Human Sciences 22 (2009), 5-36; Joelle M. Abi-Rached and Nikolas Rose, 'The Birth of the Neuromolecular Gaze', History of the Human Sciences 23 (2010), 11-36; Johnson Thornton, Brain Culture: Neuroscience and Popular Media (Rutgers University Press, 2011); Francisco Ortega and Fernando Vidal (eds), Neurocultures: Glimpses into an Expanding Universe (Frankfurt am Main: Lang, 2011).

${ }^{44}$ Walter Benjamin, 'Das Kunstwerk im Zeitalter seiner technischen Reproduzierbarkeit', in Gesammelte Werke, 2nd edn Vol. 7 (Frankfurt am Main: Suhrkamp, 1991), 350-81.

45 the official websites of these initiatives: https://www.humanbrainproject.eu/ and http://www.braininitiative.ni h.gov/index.htm. 
more fundamental than the answers delivered by the available experimental methods. Wittingly but unknowingly, 'voodoo correlations' pointed out the direction in almost 200 years of brain research engaged in soul catching. Describing the material cultures of the mind sciences as a form of animism points to their continuing success in keeping the very questions open they had once started to close. 